\title{
Characteristics of Patients with Dementia Attended in a Tertiary Outpatient Clinic in Eastern Region, Saudi Arabia
}

\author{
Mostafa Amr ${ }^{1^{*}}$, Abdel-Hady El-Gilany ${ }^{2}$, Khaid Sallam ${ }^{3}$ and Tarek Shams ${ }^{4}$ \\ ${ }^{1}$ Professor of psychiatry, College of Medicine, Mansoura University, Egypt \\ ${ }^{2}$ Professor of Public Health, Faculty of Medicine, Mansoura University, Egypt \\ ${ }^{3}$ Assistant professor of Neurology, College of Medicine, Banha University, Egypt \\ ${ }^{4}$ Professor of anesthesia and ICU, College of Medicine, Mansoura University, Egypt
}

"Corresponding author: Dr Mostafaamr, Mansoura University, Mansoura, Egypt, Tel: 00201012444197; E-mail: mostafapsy@yahoo.com

Received Date: January 24, 2014, Accepted Date: September 15, 2014, Published Date: September 22, 2014

Copyright: (c) 2014, Mostafa Amr et al., This is an open-access article distributed under the terms of the Creative Commons Attribution License, which permits unrestricted use, distribution, and reproduction in any medium, provided the original author and source are credited.

\section{Abstract}

Background: Increasing longevity and a growing older population is associated with a higher prevalence of dementia. However; research on dementia in the Gulf region is relatively scanty compared to the western world.

Objects: This is a cross sectional study to evaluate the clinical and demographic profile among 53 patients with dementia seen at the outpatient clinics of a tertiary care hospital (King Fahd Hospital), in Saudi Arabia between June 2007 and May 2011.

Method: Evaluation of patients consisted of medical history, cognitive testing, assessment of functional status (Activities of Daily Living Scale - ADL; Instrumental Activities Daily Living - IADL) and application of the Neuropsychiatry Inventory (NPI) for behavioral symptoms. Severity of dementia was evaluated based on the Clinical Dementia Rating Scale (CDR).

Results: Of the whole sample, $73.6 \%$ were males. Age was $71 \pm 5.8$ years (mean \pm SD). The types of dementia were: Alzheimer's disease (56.6\%), vascular dementia (24.5\%), mixed cases of Alzheimer and vascular dementia $(18.9 \%)$. At least one neuropsychiatric symptom was diagnosed in $98.1 \%$ of the sample. There were significant differences on some NPI symptoms such as delusions, hallucinations, apathy and aberrant motor activity.

Conclusions: Dementia is expected to be a growing problem in Saudi Arabia and the overall prevalence of neuropsychiatric symptoms has been found to be high. These findings suggest that a screening program focused on identifying symptoms of early cognitive impairment and neuropsychiatric symptoms should be included amongst the tools employed by physicians for diagnosing dementia.

Keywords: Dementia; Alzheimer's disease; Vascular dementia; Mixed dementia; Neuropsychiatric symptoms; Saudi Arabia

\section{Introduction}

The phenomenon of population aging (defined as an increase in the median age of the population) [1] is already a major social and health problem in developing countries. By the year 2025, the world will host 1.2 billion people aged 60 and over, rising to 1.9 billion in 2050 [2]. The same trend is predicted in the Eastern Mediterranean Region (EMR) including Saudi Arabia; while the proportion of the elderly population to total population was $4.8 \%$ in 2000 it expected to reach $7.9 \%$ by year 2025 and $12.9 \%$ by 2050 [3].

The increase in the aged population has been attributed to a decline in fertility and a twenty years increase in the average life span during the second half of the 20th century, [4] as a result of the rapid socioeconomic growth and increased provision of health and other social services. Among the major consequences of this growth is an increase in the prevalence of dementia, particularly Alzheimer's disease [5]. In the United States, approximately $10 \%$ of the population older than 65 years of age suffers from dementia, with Alzheimer Disease accounting for about $2 / 3$ of the cases [6]. In European countries, the prevalence of dementia is $6.4 \%$ and it increases with increasing age [7].

Dementia is characterized by cognitive, functional and behavioral symptoms. However, the current diagnosis of dementia focuses principally on, with neuropsychiatric symptoms considered to be secondary, descriptive symptoms [8]. Several studies have examined the prevalence of these symptoms. Depending on the population type studied and the methods used, prevalence can range from 61 to $97 \%$ $[8,9]$. Neuropsychiatric symptoms can induce a marked disability in patients with dementia and increase caregiver stress[10]. Furthermore, they have been found to increase rates of institutionalization and overall financial cost [11].

In the Gulf region, there is a paucity of epidemiological data on dementia in general, and Alzheimer's in particular [12-16]. Moreover, the study of dementia in our region has focused on the impairment of memory and other cognitive functions. To our knowledge, there has been no population-based estimate of the prevalence of neuropsychiatric symptoms in Saudi Arabia.

The present work is a hospital based study conducted between June 2007 and May 2011 aimed at investigation of the socio-demographic 
features and clinical features, particularly the neuropsychiatric symptoms among patients with dementia, attending a tertiary outpatient clinic in Saudi Arabia.

\section{Subjects and Methods}

Participants were recruited from people aged 60 years and above, attending the Neurology clinic, King Fahd Hospital, Hufof, Saudi Arabia from June 2007 to May 2011. The diagnosis of dementia was based on the Diagnostic and Statistical Manual of Mental Disorders Fourth Edition (DSM-IV-TR) criteria [17]. The diagnosis of Alzheimer's disease (possible or probable) was made according to the National Institute of Neurological and Communicative Disorders and Stroke - Alzheimer Disease and Related Disorders Association (NINCDS-ADRDA) criteria [18]. The diagnosis of vascular dementia followed the National Institute of Neurological Diseases and Stroke Association Internationale pour la Recherche et al. Enseignement en Neurosciences (NINDS-AIREN) criteria of probable and possible vascular dementia [19]. The diagnosis of Frontotemporal dementia was based on the consensus on clinical diagnostic criteria for Frontotemporal lobar degeneration [20]. Some patients underwent brain imaging studies for diagnosis. Patients were classified, according to dementia severity into mild, moderate and severe, based on the Clinical Dementia Rating Scale (CDR) [21].

Evaluation of patients entailed collection of demographic data, medical history and cognitive testing employing the Mini Mental State Examination (MMSE) [22]. The Activities of Daily Living Scale (ADL) [23] and the Instrumental Activities of Daily Living Scale (IADL) [24] were used to evaluate functional status while the Neuropsychiatry Inventory (NPI) [25] was employed to assess behavioral symptoms.

\section{Mini-Mental State Examination (MMSE)}

During the MMSE, a health professional asks a patient a series of questions designed to test a range of everyday mental skills. The maximum MMSE score is 30 points. A score of 24-30 is within the normal range. A score of 20 to 24 suggests mild dementia, 13 to 20 suggest moderate dementia, and less than 12 indicates severe dementia [22].

\section{Activities of Daily Living (ADLs) scoring}

The scale used to measure independence in ADLs uses ratings from 0 through 3. A score of zero represents complete independence (no impairment), while 3 represents complete dependence (impairment). Each item measures the level of impairment of the individual, regardless of the amount of help they may or may not be receiving at present. Scoring is based on how individual usually performs a task [23].

\section{The Lawton IADL (The Lawton Instrumental Activities of Daily Living)}

The scale takes 10 to 15 minutes to administer and contains eight items, with a summary score from 0 (low function) to 8 (high function), the higher the score, the greater the person's abilities [24].

\section{The Clinical Dementia Rating (CDR) scale}

The CDR rates performance in six domains: memory, orientation, judgment and problem solving, community affairs, home and hobbies, and personal care. Each domain is rated according to one of five levels of impairment: $0=$ none, $0.5=$ questionable, $1=$ mild, $2=$ moderate, $3=$ severe and CDR score of 0 indicates no dementia. CDR scores of $0.5,1,2$ and 3 indicate very mild, mild, moderate, and severe dementia, respectively. For quantitative measures for dementia severity, the rating in each of the six categories was totaled to yield the sum ranging between 0 and 18 [21].

\section{Neuropsychiatric Inventory (NPI)}

Behavioural evaluation was performed using the 12-item Neuropsychiatric Inventory (NPI) [25]. A clinician conducted a semistructured interview with caregivers, and rated the following 12 neuropsychiatric symptoms according to their severity and frequency: delusions, hallucinations, depression, anxiety, apathy, irritability, euphoria, agitation, disinhibition, aberrant motor activity, sleep disturbances and appetite changes. A screening question was used to evaluate each subarea. If the answer to this screening question was 'no', then no further questions were asked. If the answer was 'yes', then supplementary questions were asked and each behaviour rated with its frequency and severity scored as follows: behaviour frequency, from 1 to 4 points ( $1=$ occasionally, $2=$ often, $3=$ frequently, $4=$ very frequently); severity, from 1 to 3 points $(1=$ mild, $2=$ moderate, $3=$ severe). A maximum score of 12 (frequency $\times$ severity) was possible for each behaviour. A global score was obtained by adding up the scores for each individual symptom. The global score ranged from 0 (no symptoms) to 144 points. Careers were asked to base their scores on disorders observed in the patients during the previous 4 weeks.

\section{Statistical analysis}

Data was analyzed with Statistical Package for Social Sciences (SPSS) version 16. Qualitative variables were presented as numbers and percentages. The Chi-square test was used for comparison between groups. Quantitative variables were tested for normality distribution by the Kolmogorov-Smirnov test. The variables were presented as means \pm standard deviations (SDs). In normally distributed variables, analysis of variance (ANOVA) with Bonferroni multiple comparisons was used for comparison between groups. For nonparametric variables, the Kruskal-Wallis test was used for comparison between three groups. A value of $\mathrm{P} \leq 0.05$ was considered to be statistically significant. Inter-corrleation matrix was generated using Pearson correlation coefficients between total NPI and patient's demographic and clinical characteristics.

\section{Results}

A total of 53 demented patients (39 males, 14 females) were diagnosed out of 412 elderly attending the neurology clinic in the years 2007-2011 with a frequency of $12.9 \%$. The mean age at presentation was $71 \pm 5.8$ (from 60 to 87 years of age). Sociodemographic features were shown in Table 1. Co morbidity with medical disorders was found in $52.8 \%$ of patients.The most prevalent medical diagnoses wereshown in Figure 1. The neurological examination was abnormal in $41.5 \%$ of the patients; extra pyramidalsigns (tardive dyskinesia, cogwheel rigidity, rabbit movement and vermiform movements of the tongue) were found in $32.1 \%$ of them, pyramidal symptoms (spasticity) in $20.8 \%$, cerebellar in $7.5 \%$ and Soft neurological signs in $18.9 \%$ of cases (tremors, sucking, grasp, snorting, palmomentual or glabelar reflex)(Data not shown in tables). The types of dementia were: Alzheimer's disease (AD) (56.6\%) vascular dementia (VD) (24.5\%), mixed cases of Alzheimer and vascular dementia (MD) (18.9\%). A 
Citation: Amr M, El-Gilany AH, Sallam K, Shams T (2014) Characteristics of Patients with Dementia Attended in a Tertiary Outpatient Clinic in

Page 3 of 6

comparison between the average of the tests scores applied (MMSE, $\mathrm{ADL}$, IADL and CDR) was made in the 3 groups (AD, VD and $\mathrm{MD}$ ). The analysis of these data did not evidence statistically significant differences in the test scores, except in NPI where significant differences were found between Ad vs. MD and VD vs. MD (Table 2).

At least one neuropsychiatric symptom was diagnosed in $98.1 \%$ of patients Table 3 showed that in the total sample, the most prevalent symptoms were found to be anxiety (67.9\%), apathy (60.4\%), and depression (41.5\%), followed by delusions and sleep disturbances(30.2\% each). The most prevalent symptom in $\mathrm{AD}$ was apathy (76.7\%) followed by anxiety (56.7\%), agitation and irritability (23.3\% each).In the VD group, the most prevalent symptom in was anxiety (93.3\%) followed by delusions (53.9\%) and depression $(46.2 \%)$. Finally, the most prevalent symptoms in MD were anxiety (70\%), depression (70\%) and hallucination (60\%). According to KruskalWallis, there were significant differences among some neuropsychiatric symptoms including delusions, hallucinations, apathy and aberrant motor activity.

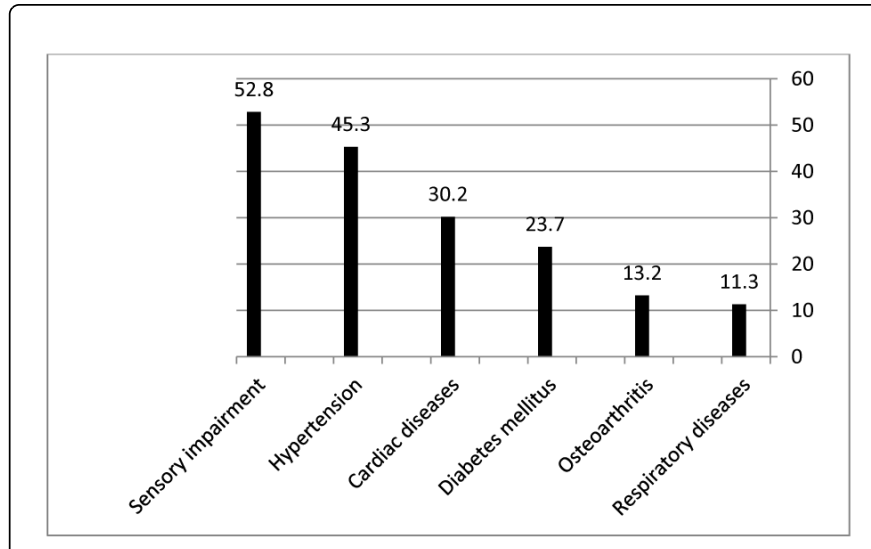

Figure 1: Associated comorbidities in patients with dementia

\begin{tabular}{|l|l|l|l|l|l|}
\hline Demographic & $\begin{array}{l}\text { AD } \\
\mathbf{N}(\%)\end{array}$ & $\begin{array}{l}\text { VD } \\
\mathbf{N}(\%)\end{array}$ & $\begin{array}{l}\text { MD } \\
\mathbf{N}(\%)\end{array}$ & $\begin{array}{l}\text { Total } \\
\text { N(\%) }\end{array}$ \\
\hline Number(\%) & $30(56.6 \%)$ & $13(24.5 \%)$ & $10(18.9 \%)$ & 53 & P \\
\hline $\begin{array}{l}\text { Age(years) } \\
\text { (Mean } \pm \text { SD) }\end{array}$ & $71.8 \pm 6.3$ & $68 \pm 5.1$ & $72.4 \pm 5.4$ & $71 \pm 5.8$ & 0.117 \\
\hline Gender(M/F) & $21(70.0) / 9(30.0)$ & $10(76.9) / 3(23.1)$ & $8(80.0) / 2(20.0)$ & $39(73.6) / 14(26.4)$ & 0.785 \\
\hline Marital status(Married/ Single) & $24(80.0) / 6(20.0)$ & $9(69.2) / 4(30.7)$ & $7(70.0) / 3(30.0)$ & $40(75.5) / 13(24.5)$ & 0.844 \\
\hline $\begin{array}{l}\text { Education(illiterate/ } \\
\text { literate) }\end{array}$ & $28(93.3) / 2(6.7)$ & $13(100.0) / 0$ & $10(100.0) / 0$ & $51(96.2) / 2(3.8)$ & 0.451 \\
\hline Living (With others / Alone) & $29(96.7) / 1(3.3)$ & $13(100.0) / 0$ & $10(100.0) / 0$ & $52(97.1) / 1(1.9)$ & 0.677 \\
\hline $\begin{array}{l}\text { Income(Unsatisfactory/ } \\
\text { Satisfactory) }\end{array}$ & $14(46.7) / 16(53.3)$ & $10(76.9) / 3(23.1)$ & $4(40.0) / 6(60.0)$ & $28(52.8) / 25(47.2)$ & 0.126 \\
\hline
\end{tabular}

Table 1: Patients' demographic and clinical characteristics

\begin{tabular}{|c|c|c|c|c|c|c|}
\hline & & $\begin{array}{l}\text { AD Mean } \pm \\
\text { SD }\end{array}$ & $\begin{array}{l}\text { VD Mean } \pm \\
\text { SD }\end{array}$ & $\begin{array}{l}\text { MD Mean } \\
\pm S D\end{array}$ & $\begin{array}{l}\text { total } \\
\text { Mean } \quad \pm \\
\text { SD }\end{array}$ & $P$ \\
\hline \multicolumn{2}{|c|}{ MMSE } & $17.5 \pm 4.97$ & $16.9 \pm 5.36$ & $\begin{array}{l}16.4 \\
5.93\end{array}$ & $\begin{array}{l}17.15 \quad \pm \\
5.2\end{array}$ & 0.916 \\
\hline \multicolumn{2}{|l|}{ ADL } & $4.6 \pm 1.5$ & $4.77 \pm 1.4$ & $4.3 \pm 1.7$ & $4.58 \pm 1.5$ & 0.804 \\
\hline \multicolumn{2}{|l|}{ IADL } & $5.6 \pm 2.2$ & $5.9 \pm 2.1$ & $4.9 \pm 2.7$ & $5.6 \pm 2.3$ & 0.747 \\
\hline \multicolumn{2}{|l|}{ NPI } & $13.9 \pm 8.9$ & $16.5 \pm 9.7$ & $\begin{array}{l}28.6 \\
11.1\end{array}$ & $\begin{array}{l}17.3 \\
10.9\end{array}$ & $\leq 0.001$ \\
\hline \multirow{3}{*}{$\begin{array}{l}\mathrm{CDR} \\
\mathrm{N}(\%)\end{array}$} & Mild & $12(39.99 \%)$ & $5(38.46 \%)$ & $3(30 \%)$ & $20(37.7 \%)$ & \multirow{3}{*}{0.801} \\
\hline & $\begin{array}{l}\text { Moderat } \\
\mathrm{e}\end{array}$ & $14(46.66 \%)$ & $5(38.46 \%)$ & $4(40 \%)$ & $23(43.4 \%)$ & \\
\hline & Severe & $4(13.33 \%)$ & $3(23.076 \%)$ & $3(30 \%)$ & $10(18.9 \%)$ & \\
\hline
\end{tabular}

Table 2: Distribution of test scores and scales according to dementia type

\begin{tabular}{|l|l|l|l|l|l|l|}
\hline & AD & VD & MD & Total & $\mathbf{X}^{2}$ & $\mathbf{P}$ \\
\hline Delusion & $5(16.7 \%)$ & $7(53.9 \%)$ & $4(40 \%)$ & $16(30.2 \%)$ & 6.512 & 0.039 \\
\hline $\begin{array}{l}\text { Hallucinatio } \\
\text { ns }\end{array}$ & $4(13.3 \%)$ & $3(23.1 \%)$ & $6(60 \%)$ & $13(24.5 \%)$ & 8.843 & 0.012 \\
\hline Agitations & $7(23.3 \%)$ & $4(30.8 \%)$ & $4(40 \%)$ & $15(28.3 \%)$ & 1.078 & 0.583 \\
\hline Depression & $9(30 \%)$ & $6(46.2 \%)$ & $7(70 \%)$ & $22(41.5 \%)$ & 5.096 & 0.078 \\
\hline Anxiety & $17(56.7 \%)$ & $12(92.3 \%)$ & $7(70 \%)$ & $36(67.9 \%)$ & 5.312 & 0.070 \\
\hline Euphoria & $1(3.3 \%)$ & $1(7.69 \%)$ & $2(20 \%)$ & $4(7.6 \%)$ & 2.986 & 0.225 \\
\hline Apathy & $23(76.7 \%)$ & $5(38.5 \%)$ & $4(40 \%)$ & $32(60.4 \%)$ & 7.673 & 0.022 \\
\hline Disinhibition & $2(6.7 \%)$ & $2(15.4 \%)$ & $2(20 \%)$ & $6(11.3 \%)$ & 1.611 & 0.447 \\
\hline Irritability & $7(23.3 \%)$ & $4(30.8 \%)$ & $3(30 \%)$ & $14(26.4 \%)$ & .339 & 0.844 \\
\hline AMA & $4(13.3 \%)$ & $2(15.4 \%)$ & $5(50 \%)$ & $11(20.8 \%)$ & 6.433 & 0.040 \\
\hline Apetite & $5(16.7 \%)$ & $4(30.8 \%)$ & $4(40 \%)$ & $13(24.5 \%)$ & 2.568 & 0.277 \\
\hline Sleep & $9(30 \%)$ & $3(23.1 \%)$ & $4(40 \%)$ & $16(30.2 \%)$ & 0.769 & 0.681 \\
\hline
\end{tabular}

Table 3: Prevalence of NPI according to dementia type 


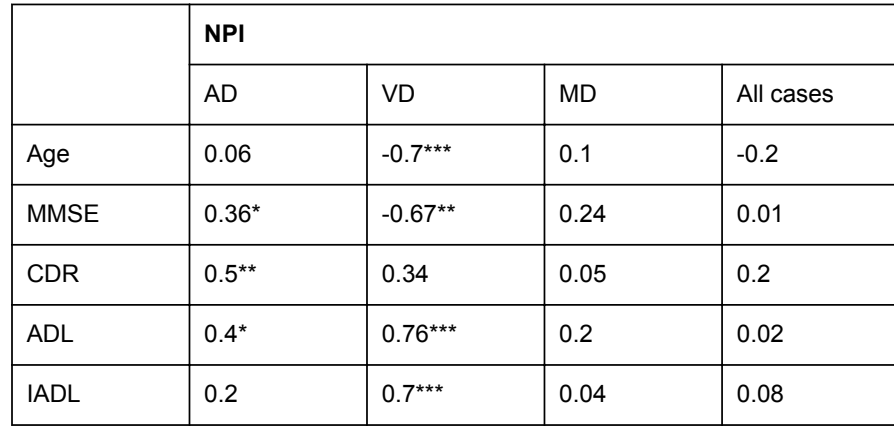

Table 4: Correlation coefficients ( $\mathrm{r}$ ) between NPI and different quantitative variables in the three groups and in total population, ${ }^{\star} \mathrm{P} \leq$ $0.05,{ }^{* *} \mathrm{P} \leq 0.01,{ }^{* *} \mathrm{P} \leq 0.001$

Hallucinations and aberrant motor activity were more prevalent in MD group (60\% and 50\% respectively), delusions were more prevalent in VD group (53.9\%), and apathy appeared to be more prevalent in $\mathrm{AD}$ group (76.7\%). In Table 4, the inter-correlation matrix showed that there a significant positive correlation between total NPI and MMSE and CDR in AD group. However, in VD group NPI show significant negative correlation with age and MMSE and significant positive correlation with ADL and IADL.

\section{Discussion}

Epidemiological reports about dementia in elderly in non-western populations, especially in developing countries including Saudi Arabia have not been widely known. The prevalence of dementia in this study $(12.9 \%)$ is similar to reported studies from Canada 8\% [26], Italy $9.8 \%$ [27] and Netherlands $13.3 \%$ [28], but much higher than a previous hospital based study in Saudi Arabia 0.2\% [12] and other countries. Farrag et al., 1998, [29] reported a prevalence of $4.5 \%$ in As suit governorate-Egypt. In a two phase study done in urban community in Beijing [30], the prevalence of dementia is $2.68 \%$ in the elderly above 60 years and older and in a study in India [31], the prevalence of dementia in the elderly age 65 years and above was $2.44 \%$.This difference in prevalence rate may be explained by: first, difference in survival rates, between 1980 and 2011, Saudi Arabia's life expectancy at birth increased by 11.7 years, (from 62.2 to 73.9 years) [3]; second, the relatively younger age of presentation in our study and higher rates of mild and moderate cases $(81.1 \%)$ than the previous studies which reflect increased awareness of the relatives and the professionals about dementia ; third, high rates of co-morbidity in our study $(52.8 \%)$ particularly Hypertension, cardiac diseases and diabetes (45.3\%, 30.2\% $23.7 \%$ ) could explain the high rate of encountered dementia cases, fourth, due to some methodological difference between our study and the above studies.

The patients' average age in our study was of the same range as most of the previous studies in Saudi Arabia [12], Brazil [32] and Malaysia [33]. A clear preponderance of males was also observed in the total sample and among patients with $\mathrm{AD}$. This is contrary to the findings of similar studies that reported higher prevalence rates for dementia among females in several geographical areas and these differences were clear among the oldest age groups [34]. These results may not reflect the true prevalence of dementia of course. Women may not attend hospitals as frequently as men since for cultural reasons; they are totally dependent on men to take them there. Furthermore, women in Eastern societies are thought to be more tolerant of both physical and psychological pain than western women, which may be considered culturally normative for them [35].

The Saudi culture and traditional social values dictate high respect for care of elderly by members of extended family [36] and this may explain the small number of elderly in the study who were living alone compared to elders in other communities .More than three- fourths of the sample (75.5\%) were married; considering the advanced patients' ages, those are not surprising figures. The majority of patients were illiterate $(96.2 \%)$ as the educational opportunities were scarce by the time of their childhood and youth. Deficiency of education can lead to a quick and early developing memory loss. Early education affects neocortical synaptic density and increase cognitive capacity, therefore protecting one from dementia [37].

Reviewing the prevalence of dementia in community studies, Lopes and Bottino, 2002 [34] observed that AD was the most prevalent cause of dementia followed by VD and $\mathrm{MD}$ in all geographic regions researched. Mixed dementia represents a frequent pathology in older people where both degenerative and vascular pathology present in the same time. In the present study the $\mathrm{AD}$ was the most frequent diagnosis in the sample studied. The prevalence found was $56.6 \%$ and $\mathrm{AD}$ associated to $\mathrm{VD}$ (MD) $18.9 \%$ followed by $\mathrm{VD}$ (24.5\%) with patients being predominantly at mild and moderated stages according to CDR (81.1\%). Our findings are also similar to those described in previous studies. Ogunniyi et al., 1998 [12] found $51.95 \%$ prevalence of Saudi patients who presented $\mathrm{AD}$ of late onset, $18.2 \%$ vascular dementia and $15.6 \%$ Alzheimer disease and vascular dementia. Shelley and Khabouri, 2007[15] showed that $\mathrm{AD}$ was the commonest dementia subtype seen in 61 patients (52.6\%), while $24.1 \%$ had vascular dementia and $9.5 \%$ constituted fronto temporal lobar degeneration at the Royal Hospital, Muscat, Oman. Silva et al. [38] at a neurology ambulatory of tertiary hospital in Brazil evidenced a sample with vascular dementia prevalence of $24.9 \%$ and $\mathrm{AD}$ of $23.7 \%$, with predominance of mild and moderate cases ( $83.5 \%$ of cases).

The neuropsychiatric symptoms in elderly patients with dementia are very common and serious when the disease is well established, but can also be present months or years before the diagnosis and precede the beginning of cognitive deficits in patients with $\mathrm{AD}$ [39]. In this study NPI has been used with the purpose of investigating the presence of psychiatric morbidity in patients with dementia. The occurrence of at least one psychiatric symptom was observed in almost all patients of our sample (98.1\%), probably because it was a specialized neurology clinic in of a tertiary hospital. Among the most common symptoms, anxiety, apathy, depression, delusions, sleep disturbances and agitation had been found.

The relation between the prevalence of neuropsychiatric symptoms and the severity of dementia varied widely in the studies previously mentioned. For example, Tatsch et al. [40] found 7.7\%, $16 \%$ and $23.4 \%$ of agitation/aggressiveness prevalence and $15.4 \%, 28 \%$ and $47 \%$ of abnormal motor behavior in patients grouped into dementia severity, according to the scale $\mathrm{CDR}$ in $0.5,1$ and 2-3.On the contrary, Fernndez Martinez et al. [41] did not observe any significant effects of age, gender, education or dementia severity on the prevalence of neuropsychiatric symptoms. In our sample, the frequency of neuropsychiatric symptoms was not affected with the severity of the disease or other demographic, cognitive and behavioral measures. 
Prevalence of neuropsychiatric symptoms was similar for the different types of dementia with the exception of delusions, hallucinations, apathy and aberrant motor activity. Hallucinations and aberrant motor activity were more prevalent in MD group; delusions were more prevalent in VD group, whereas, apathy appeared to be more prevalent in $\mathrm{AD}$ group.

Studies of patients with $\mathrm{AD}$ and other types of dementia from the USA and Brazil yielded similar results. A study of prevalence of neuropsychiatric symptoms in the Brazilian elderly from the community. Apathy (53.3\%), depression (38.3), sleeping disorder (38.3\%) and anxiety (25\%) were the most frequent symptoms in the samples of patients with $\mathrm{AD}$ from that study [40]. Furthermore, the Cardiovascular Health Study [42] indicated that with the exception of aberrant motor activity, which was more prevalent and severe in patients with $\mathrm{AD}$. Other studies have shown similar levels of prevalence of depression for $\mathrm{AD}[40,42]$. Psychotic features appear to be frequent in patients with $\mathrm{VD}$, with reports of delusions in 8-50\%, visual hallucinations in $13-25 \%$ and delusional misinterpretation in 26-27\% [43]. The Cache County study of ageing showed that delusions were common in AD than in VD patients [44]. However, in another large, population study using the NPI, delusions did not differ between patients with $\mathrm{AD}$ and other non-AD dementia [42].

The strengths of our study are: (1) it evaluates and reports on the demographic profile for the patients with dementia in a tertiary Saudi Neurology clinic; (2) it employs many neuropsychological tools and standardized tests; (3) it is the first population- based study to describe the neuropsychiatric symptoms of patients with dementia in Saudi Arabia

\section{Limitations of the Study}

Although it is an epidemiological study, the sample group only includes patients with dementia from a single facility; and therefore the findings cannot be extended to the community. These at best reflect the pattern of hospital utilization, which is motivated by a variety of factors. Hence the findings need to be confirmed by community based studies.

\section{Conclusions}

Dementia is expected to be a growing problem in Saudi Arabia and other Arab countries; the prevalence of dementia in the outpatient department of a tertiary care setting in Eastern region is actually higher than previously reported in the same region. Moreover, the overall prevalence of neuropsychiatric symptoms has been found to be high and there is clinical difference in the prevalence of some individual symptoms in certain types of dementia. These findings suggest that a screening program focused on identifying symptoms of early cognitive impairment (MMSE) and neuropsychiatric symptoms (NPI) should be included amongst the tools employed by physicians for diagnosing dementia.

\section{References}

1. Bhende A, Kanitkar T (1997) Principles of population studies. 6th revised edition, Himalaya Publishing House, Mumbai 137-140.

2. World Population Prospects (2003) The 2002 Revision, Highlights. New York: United Nations Population Division. (ESA/P/WP 180).

3. WMWR Morb mortal wkly Rep (2003) Trends in aging US and worldwide 52: 101-104,106.
4. Hafez G, Bagchi K, Mahaini R (2000) Caring for the elderly: a report on the status of care for the elderly in the Eastern Mediterranean Region. East Mediterr Health J 6:636-643.

5. Ferri CP, Prince M, Carol C, Brayne C, Brodaty H, et al. (2005) Global prevalence of dementia: a Delphi consensus study. Lancet 366:2112-2117.

6. Hendrie HC (1998) Epidemiology of Dementia and Alzheimer's disease. Am J Geriatr Psychiatry 6: S3-S18.

7. Lobo A, Saz P, Marcos G, Dia JL, Camara DL (1995) The prevalence of dementia and depression in the elderly community in a southern European population. The Zaragoza Study. Arch Gen Psychiatry 52: 497-505.

8. Lyketsos CG, Sheppard JM, Steinberg M, Tschanz JA, Norton MC, et al. (2001) Neuropsychiatric disturbance in Alzheimer's disease clusters into threegroups: the Cache County study. Int J Geriatr Psychiatry 16: 1043-1053.

9. TasconeLdos S, Marques Rde C, Pereira EC, Bottino CM (2008)Characteristics of patients assisted at an ambulatory of dementia from a university hospital. Arqneuropsiquitar 66:631-635.

10. Swearer JM, Drachman DA, O’Donnell BF, Mitchell AL (1998) Troublesome and disruptive behaviors in dementia. Relationships to diagnosis and disease severity. J Am GeriatrSoc 36: 784-790.

11. Hebert R, Dubois MF, Wolfson C, Chambers L, Cohen C (2001) Factors associated with long term institutionalization of older people with dementia: data from the Canadian Study of Health and Aging. J Gerontol A Biolsci Med Sci 56: M693-M699.

12. Ogunniyi A, Daif AK, Al-Rajeh S, AbdulJabbar M, Al-Tahan AR, AlBunyan M,et al. (1998) Dementia in Saudi Arabia: experience from a university hospital. Acta Neurol Scand 9:116-20.

13. Ghubash R, El-Rufaie O, Zoubeidi T, Al-Shboul QM, Sabri S M (2004) Profile of mental disorders among the elderly United Emirates population: Sociodemographic correlates. International Journal of Geriatric Psychiatry 19: 344-351.

14. Ramadan M, Sulaiti E (2005) Causes of Dementia In Qatar. Middle East Journal of Age and Ageing 2: 72-75.

15. Shelley BP, Khabouri J (2007) The spectrum of dementia: frequency, causes and clinical profile. A national referral hospital-based study in Oman.Dement Geriatr Cogn Disord 24: 280-7.

16. Sallam K, Amr M (2012) Prevalence of dementia and associated risk factors in a tertiary hospital in Saudi Arabia. MEJPA 3:15-23.

17. American Psychiatric association (2000)Diagnostic and Statistical Manual of Psychiatric Disorders 4.Ed. (DSMIV-TR) Washington DC:APA.

McKhann G, Drachman D, Folstein M, Katzman R, Price D, et al. (1984) Clinical diagnosis of Alzheimer's disease. Neurology 34:939-944.

18. Roman GC, Tatemichi TK, ErkinjunttiT, Cummings JL, Masdeu JC, Garcia JH, et al. (1993) Vascular dementia: diagnostic criteria for research studies. Neurology 43:250-260.

19. Neary D, Snowden JS, Gustafson L,PassantU, Struss D, et al. (1998) Frontotemporal lobar degeneration a consensus on clinical diagnostic criteria. Neurology 51: 1546-1554.

20. Chaves ML, Camozzato AL, Godinho C, KochhannR, Schuh A, et al. (2007) Validity of the clinical dementia rating scale for the detection and staging of dementia in Brazilian patients. Alzheimer Dis Assoc Disord 21:210-217.

21. Folstein MF, Folstein SE, McHugh PR (1975) "Mini-Mental State": a practical method for grading the cognitive state of patients for the clinician. J Psychiatr Res 12: 189-198.

22. Katz A, Ford AB, Moskowitz RW, Jackson BA, Jaffe MW (1963) Studies of illness in the aged. The index of ADL: a standardized measure of biological and psychological function JAMA 185:914-919.

23. Lawton MP, Brody EM (1969) "Assessment of older people: Selfmaintaining and instrumental activities of daily living." Gerontologist 9: 179-186. 
Citation: Amr M, El-Gilany AH, Sallam K, Shams T (2014) Characteristics of Patients with Dementia Attended in a Tertiary Outpatient Clinic in Eastern Region, Saudi Arabia. J Psychiatry 17: 1000143. doi:10.4172/1994-8220.1000143

Page 6 of 6

24. Cummings JL, Mega M, Gray K, Rosenberg- Thompson S, et al. (1994) The Neuropsychiatric Inventory: comprehensive assessment of psychopathology in dementia. Neurology 44: 2308-2314.

25. Lindsay J, Sykes E, Mc Dowell I, Verreault R, Laurin D (2004) More than the epidemiology of Alzheimer's disease: contribution of the Canadian study of health and Aging Can J Psych 49: 83-91.

26. Ferini-Strambi A, Marcone P, GaranchiF,Danelon F, Zamboni M, et al. (1977) Dementing disorder in North Italy: prevalence study in Viscovata, Cremona Province. Eur JEpidemiol13: 201-4.

27. McCullagh CD, Craig D, McIlroy SP, Passmore AP (2001) Risk factors for dementia. AdvPsychiatr Treatment 7: 24-31.

28. Farrag AF, Farwiz HF, Khedr EM, Mahfouz RM,Omran SM (1998) Prevalence of Alzheimer's disease and other dementing disorders: in Assiut-Upper Egypt Study. Dement and Geriatr Cogn Disord 9: 322-8.

29. Wang W, Wu S, Cheng X, Dai H, Ross K, et al. (2000)Prevalence of Alzheimer's disease and other dementing disorders in an urban community of Beijing, China. Neuroepidemiology 19: 194-200.

30. Vas CJ, Pinto C, Panikker D, Noronha S,Deshpande N, et al. (2000) Prevalence of dementia in an urban Indian population. Int Psychogeriatr 13: 439-50.

31. Vale FA, Miranda SJ (2000)Clinical and demographic features of patients with dementia attended a tertiary outpatient clinic.ArqNeuropsiquiatr60:548-52.

32. Norlaily H, Azidah AK, Asrenee AR, Rohayah H, Juwita S (2009) Proportion of dementia and its associated factors among elderly patients attending outpatient clinics of UniversitiSains Malaysia Hospital.Med J Malaysia64:140-5.

33. Lopes MA, Bottino CM (2002)Prevalence of dementia in several regions of the world: analysis of epidemiologic studies from 1994 to 2000.ArqNeuropsiquiatr 60:61-9.

34. El-Sayed S, Maghraby H, Hafeiz H, Buckley M (1986) Psychiatric diagnostic categories in Saudi Arabia. Acta Psychiatr Scand 74:553-554
35. Al-Sabaie A (1989) Psychiatry in Saudi Arabia: cultural perspectives. Trans Psychiatr Res rev 26:245-262.

36. Kukul WA,BowenJD(2002) Dementia epidemiology. Med Clin North Am 86: 20.

37. Silva DW, Damassceno BP (2002) Dementia in patients of hospital das clinicas da UNICAMP. Arq Neuropsiquiatr. 60:966-999.

38. Peters KR, Rockwood K, Black SE, Bouchard R, Gauthier S, et al. (2006) Characterizing neuropsychiatric symptoms in subjects referred to dementia clinics. Neurology 66:523-528.

39. Tatsch MF, Bottino CM, Azevedo D, Hototian SR, Moscoso MA, et al. (2006) Neuropsychiatric symptoms in Alzheimer disease and cognitively impaired, nondemented elderly from a community- based sample in Brazil: prevalence and relationship with dementia severity. Am J Geriatr Psychiatry 14: 438-445.

40. Fernández Martínez M, Castro Flores J, Pérez de lasHeras S,Mandaluniz Lekumberri A, Gordejuela Menocal M, et al. (2008) Prevalence of Neuropsychiatric Symptoms in Elderly Patients with Dementia in Mungialde County (Basque Country, Spain). Dement GeraitrCogn Discord 25:103-108.

41. Lyketsos CG, Lopez O, Jones B, Fitzpatrick AL, Breitner J, et al. (2002) Prevalence of neuropsychiatric symptoms in dementia and mild cognitive impairment: results from the cardiovascular health study. JAMA 288: 1475-483.

42. Arsland D,Bellard C (2004) Psychiatric issues in non-Alzheimer dementias. ClinNeurosci Res 3: 397-412.

43. Lyketsos CG, Steinberg M, Tschanz JA, Norton MC, Steffens DC, et al. (2000) Mental and behavioral disturbances in dementia: findings from the Cache County study on memory andaging.Am J Psychiatry 157: 708-14. 